\title{
La construcción de realidades abstractas: un ensayo sobre la investigación territorial
}

\author{
Fábio Duarte-de AraúJo-SiLVA*
}

\section{Resumen}

En este artículo se analiza cómo los datos secundarios básicos para la investigación urbana y regional se utilizan para construir representaciones sociales de la realidad. Se explora lo que dichos datos muestran de la realidad y, principalmente, lo que revelan sobre su proceso de construcción. En dicho proceso se identifican dos desafíos para la formación del investigador: a) reconocer que gran parte del trabajo analítico tendrá como base datos secundarios, que no son un espejo de la realidad sino una representación construida con presuposiciones tanto ideológicas como metodológicas y $b$ ) estimular al investigador para que identifique la construcción ideológica y metodológica de los datos como un elemento de reflexión con diversos desafíos científicos. Como ejemplo, se consideran los estudios territoriales en Brasil.

Palabras clave: investigación urbana y regional, representación de la realidad, análisis de datos, ensayo epistemológico.

\section{Abstract}

In this paper we analyse how the secondary basic data for urban and regional research is used to build up social representations of reality. We explore what this data shows about reality, and more importantly, what it unravels about its construction process. In this process we identify two challenges for the training of researchers: a) the recognition that a big part of the analytical work is based on secondary data which is not a mirror of reality but a representation built from ideological and methodological assumptions; and b) the stimulation of researchers to identify the ideological and methodological construction of data as an element of reflection on different scientific challenges. We consider the case of territorial studies in Brazil as an example.

Keywords: regional and urban research, reality representation, data analysis, epistemological essay.

\footnotetext{
*Pontificia Universidad Católica de Paraná, Brasil. Correo-e: duarte.fabio@pucpr.br.
} 


\section{Introducción: la abstracción de la realidad}

Uno de los primeros desafíos para formar investigadores en cuestiones urbanas y regionales, principalmente cuando hay implicación personal con los asuntos trabajados, es demostrar que, en la investigación, el territorio es una realidad abstracta. Epistemológicamente, sólo conocemos la realidad por medio de sus representaciones. Como escribió Charles Peirce (1997), "el grado más elevado de la realidad sólo es alcanzado por los signos”. O Lucrécia Ferrara (2003: 37), quien dice que: "el pensamiento se construye en la construcción del lenguaje. Nuestro ejercicio de conocimiento está conectado a los lenguajes que disponemos para el ejercicio del juego reflexivo de la razón, o sea, el lenguaje es otro nombre para la mediación indispensable del conocimiento del mundo".

Ineludiblemente, la aproximación a la realidad pasa por un proceso de abstracción y de reducción. La reducción puede ser entendida como una premisa temática de la investigación. Si, por ejemplo, se estudia el problema de la ociosidad inmobiliaria en las zonas centrales de la ciudad, no se podrán detallar todos los aspectos de cada familia o las características de cada inmueble. Necesariamente habrá generalizaciones, reducciones hechas para que sea posible manejar la información. Y toda la carga emotiva que puede existir en el investigador en relación con su objeto será destituida de valor analítico explícito. Inmuebles ociosos en las zonas centrales urbanas cuyas calles son refugio para una población sin vivienda se reduce, en principio, a la relación del número de inmuebles ociosos frente al número de personas sin vivienda. El aislamiento de casos puede traer luces a las cuestiones que escapan de las abstracciones, pero sin generalizaciones (abstracciones y reducciones) no se hace investigación.

Es así como intervienen dos problemas comunes para el investigador en cuestiones urbanas y regionales.

El primer problema (llamémoslo de ahogamiento en números) se refiere a la conciencia de que la representación de la realidad revela menos la realidad y más la capacidad (o limitación) intelectual del investigador de construir representaciones. Al mismo tiempo, y justamente porque la investigación urbana y regional trata de representaciones (abstracciones y reducciones) de la realidad, se debe tener más cuidado para que los datos (representaciones) sean lentes que analicen una realidad, no espejos de las creencias ideológicas del investigador. Por ejemplo, el producto interno bruto (PIB) per cápita en Brasil es de US\$2,8 mil 
-lo que coloca a ese país en una relativa buena posición en el escenario mundial: en el lugar 63 entre 177 naciones- (UNDP, 2005). Esa información, por lo tanto, puede ser usada para resaltar la calidad de vida del brasileño, que no se refleja si se compara con la distribución territorial de la media salarial por municipios, o hasta del PIB per cápita por estado -donde se ven diferencias del PIB anual per cápita por encima de $\mathrm{R} \$ 11$ mil (us $\$ 5$ mil) en los estados de Río de Janeiro, São Paulo y en el Distrito Federal, hasta valores anuales próximos a R \$2 mil en Maranhão o Piauí (IBGE, 2002).

El segundo problema (llamémoslo de búsqueda de una realidad perdida) normalmente ocurre en dos vertientes. Una es donde el investigador intenta hacer una aproximación total entre la representación y la realidad. Un pasaje de Jorge Luis Borges (1960: 103) sirve como ilustración:

En aquel Imperio, el Arte de la Cartografía logró tal perfección que el mapa de una sola provincia ocupaba toda una ciudad, y el mapa del imperio, toda una provincia. Con el tiempo, esos mapas desmesurados no satisficieron y los Colegios de Cartógrafos levantaron un mapa del imperio, que tenía el tamaño del imperio y coincidía puntualmente con él. Menos adictas al estudio de la cartografía, las generaciones siguientes entendieron que ese dilatado mapa era inútil y no sin Impiedad lo entregaron a las Inclemencias del sol y de los inviernos. En los desiertos del Oeste perduran las despedazadas ruinas del mapa, habitadas por animales y por mendigos; en todo el país no hay otra reliquia de las disciplinas geográficas.

Lo que se aprecia aquí, y que a veces le ocurre a los investigadores, es que las tentativas de hacer una representación minuciosa que abarque la mayor parte de los aspectos posibles con todas sus variaciones probables, será un esfuerzo perdido. Antes de que la representación quede lista, el objeto ya se alteró y la representación -y, en consecuencia, la investigación- caducó.

Otro aspecto de la búsqueda de una realidad ideal es cuando el investigador se encanta con la representación e intenta sustituir la realidad con esa representación. Otra vez, la literatura ilustra esta situación:

Kublai era un atento jugador de ajedrez [...] Pensó: Si cada ciudad es como una partida de ajedrez, el día en que yo conozca sus reglas finalmente poseeré mi imperio, a pesar de que jamás conseguiré conocer todas las ciudades que éste contiene. [Pero] Con el propósito de desmembrar sus conquistas las redujo a la esencia, Kublai hubo alcanzado el extremo de la operación: la conquista definitiva, delante de la cual 
los multiformes tesoros del imperio no pasaban de involucres ilusorios, se reducía a una tesuela de madera pulida: la nada... (Calvino, 1972: 119-120).

Aquí Calvino muestra cómo Kublai construyó un modelo de representación sofisticado que le satisfacía de tal modo que se sintió capaz de construir la realidad sin tener contacto con ella -o sin que, de hecho, ella existiera necesariamente-.

\section{El territorio y el denominador común}

El proceso de representación de la realidad territorial (urbana o regional), para que se tengan datos e información manejables para el análisis, pasa por la adopción o construcción de máximos denominadores comunes -etapa muchas veces frustrante porque envuelve la abstracción y reduce la realidad, sin embargo, ineludible-.

Así, representar la realidad en datos tiene como principal objetivo transformarla en partes manipulables, mensurables y comparables. Algunos de esos datos, de esos máximos denominadores comunes, son neutros, no sujetos a interpretaciones dudosas. Son, básicamente, el número de personas, el sexo, la edad y la muerte. No hay cómo cuestionar la cantidad en un grupo de personas (se puede cuestionar el método, pero no el hecho), el sexo y la edad de ellas, o si están vivas. A partir de allí, todos los otros datos son sujetos a discusiones conceptuales (Santos y Silveira, 2003).

Tomemos algunos datos a su vez derivados del cruce de otros datos o que incluyen conceptos, pero que tienden a usarse como básicos: escolaridad, población urbana, población rural, color de la piel, raza, religión, número de empleos e inversiones. Existe, primero, la cuestión de quién respondió. En cuanto al color de la piel, por ejemplo, la población brasileña tuvo un aumento de declarantes negros entre 1995 y 2003 . En investigaciones realizadas por el Instituto Datafolha y el Núcleo de Opinión Pública (NOP), de la Fundación Perseu Abramo, en centros urbanos, el porcentaje de entrevistados que se clasifican espontáneamente de color negro o de raza negra subió de 7 a 12\% (y en la categoría pardo, aumentó de 6\% a 11\%) (NOp, 2003). ¿Qué sucedió? ¿Un aumento en la tasa de natalidad de negros y una disminución de blancos? ¿O una disminución de prejuicios raciales que hizo que los negros se sintieran cómodos al declararse así? ¿ $\mathrm{O}$ se debe a programas puntuales (como las cotas universitarias) que estimulan el cambio en las declaraciones anteriores? Como indica el coordinador de la investigación, Gustavo Venturi (NOP, 2003), 
ese aumento en la autodeclaración como negros "apunta para una mayor definición de la identidad racial en detrimento de la categoría 'morena', ella sí muy difusa y escamoteadora de la cuestión racial", además de favorecer la toma de conciencia acerca de los conflictos, primer paso hacia la posibilidad de superarlos.

En cuanto al número de empleos: si sólo se consideran los formales, en Brasil tenemos un número de $88.5 \%$ de la población económicamente activa empleada en el 2004 (IBGE, 2005). Pero si se considera la tasa de informalidad, sabemos que de 1997 al 2003, casi la totalidad de las empresas no agrícolas con hasta cinco empleados formaba parte del sector informal -de 99 a 98\%, respectivamente-, además de un aumento de $8 \%$ en los puestos de trabajo informales en el periodo (IBGE, 2003).

Otro factor que complica la construcción de los máximos denominadores comunes es su espacialización. En la figura i se muestra la distribución por estados de la población trabajadora de entre 10 y 14 años.

Tan interesante como los análisis que se pueden realizar con apoyo del mapa (como la concentración de trabajadores infantiles en el nordeste brasileño) es la discusión de las concepciones de esos datos: ¿por qué esta división en edades? No es coinci-

Figura I

Población trabajadora de entre 10 y 14 años

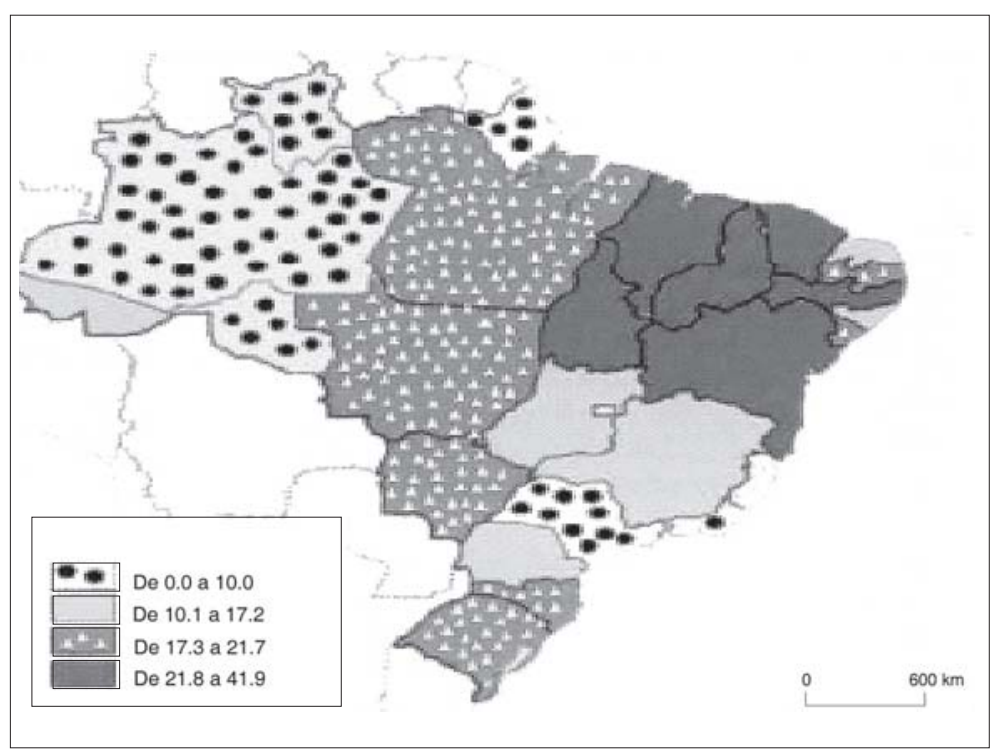

Fuente: IBGE, 2000. 
dencia que éstas sean de una etapa de escolaridad -y esta misma de una de las agrupaciones del Instituto Brasileño de Geografía y Estadística, IBGE-. Y ¿qué significa trabajar? ¿El trabajo doméstico también se considera? Los límites administrativos de los estados también son un factor; probablemente las características de las ciudades del norte del estado de Paraná son más semejantes a las del suroeste de São Paulo que a las del resto del estado, o el comportamiento en las regiones metropolitanas es diferente al del interior. Lo que queremos destacar es que la propia elección de los datos y su caracterización influirán en la marcha de la investigación y en eventuales tomas de posición.

En diversos momentos, se usan datos compuestos e indirectos; es decir, mientras los datos neutros (número de personas) y los derivados (número de personas empleadas) señalan sólo lo que se proponen -la cantidad de personas empleadas en determinada región-, los datos compuestos e indirectos tienen menos relevancia como un indicativo directo y más como un indicio. Éstos son útiles para enriquecer la lectura de la realidad, pero permiten menos comparaciones entre unidades diferentes. Un ejemplo es la utilización de indicadores de posesión de equipamientos electro-electrónicos, usados menos para señalar de hecho quiénes poseen tal o cual equipamiento, y más como dato indirecto para conocer la concentración de riqueza.

El Criterio Brasil, elaborado por la Asociación Brasileña de Empresas de Investigación (ABEP), fue realizado inicialmente sobre el banco de datos del Levantamiento Socioeconómico (LSE) del Instituto Brasileño de Investigaciones (ІвоРе), que estudió 20 mil domicilios en 1993, con números actualizados en el 2000. Usado en investigaciones de campo cuando involucran entrevistas para hacer la segmentación socioeconómica de la población, el Criterio Brasil está basado en el grado de instrucción del jefe de la familia y en la posesión de ítems de consumo, principalmente electrodomésticos (ABEP, 2003).

Este método parte de algunas dificultades que las empresas encuentran en las investigaciones oficiales: el intervalo de 10 años entre éstas a todos los domicilios realizadas por el IBGE, el encuadramiento de los datos en delimitaciones geoadministrativas y el dato económico basado en la renta del jefe de familia levantada por respuesta espontánea. La búsqueda de otras formas de segmentación socioeconómica apoyadas en indicadores indirectos es el gran valor del Criterio Brasil.

Sin embargo, una relativa estabilidad económica en la última década, las facilidades de financiación en la adquisición de bie- 
nes (mucho en función de esta misma estabilidad) y la caída constante de los precios de esos bienes tecnológicos hacen que el Criterio Brasil pierda su fuerza y validez, como señala Paulo de Martino Jannuzzi (2003).

Pero el propio IBGE, a partir del censo de 2000, produjo mapas con la posesión de bienes tecnológicos. Existen mapas temáticos con posesión de horno de microondas, computadoras o televisores por domicilio. Esta información, principalmente cuando se cruza con la red de energía eléctrica en el país, índices de alfabetización y renta media familiar, propician inferencias estimulantes al investigador.

El gran problema de esos datos -además de la división geográfica, que puede ser detallada-, es que se mantienen estáticos en el tiempo, cosa que no sucede con la dinámica del mercado de electrodomésticos, como muestra la gráfica I.

\section{Gráfica I}

Ventas y precio de televisores de cristal líquido

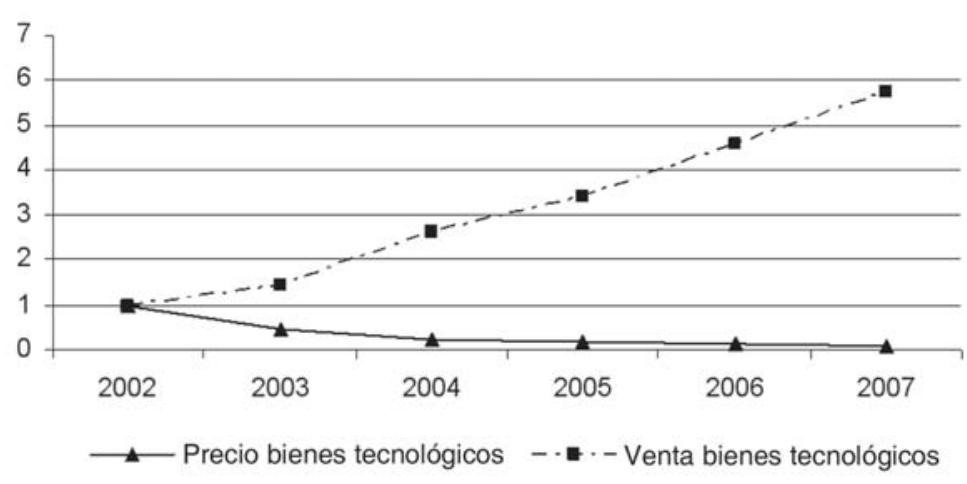

Fuente: Suppli, Revista Exame, 31 de marzo de 2004.

Tomamos un ítem tecnológico aún no diseminado por todas las clases sociales (diferente de la televisión, presente en más de $90 \%$ de los domicilios brasileños). En sólo cuatro años la proyección de ventas de los televisores de cristal líquido muestra un incremento en dólares de casi $600 \%$-esto con un precio reducido en $90 \%$, lo que señala que el crecimiento en el número de aparatos vendidos es aún mayor.

Los problemas intrínsecos a los factores considerados en la composición de esta segmentación socioeconómica estimularán la búsqueda por alternativas conceptuales y metodológicas, como 
las de Jannuzzi (2003), que considera una cierta clasificación socioocupacional, tomando en cuenta, además del ingreso y de la escolaridad, el estatus socioeconómico de las ocupaciones (donde médicos, ingenieros y profesores universitarios tienen un estatus máximo próximo a 100; y empleados domésticos o autónomos en la agropecuaria tienen estatus mínimo próximo a 1). También considera, en la depuración de la segmentación, el porcentaje entre las agrupaciones profesionales de estatus socioeconómico de contribuyentes en sanidad, riesgo de desempleo, etc. En Brasil, esa segmentación socioocupacional es poco utilizada, según Jannuzzi (2003), por el desconocimiento de las escalas socioocupacionales existentes y por la facilidad operacional y el relativo poder discriminatorio de las escalas basadas en la posesión de bienes de consumo durable. A pesar de la superioridad teórica aclamada por el autor (Jannuzzi, 2003: 254), la construcción de esa escala, con factores como riesgo de desempleo, también necesitan de generalizaciones conceptuales (¿̇e considerarán sólo empleos formales?).

Un ejemplo específico sobre el empleo es una investigación hecha en la ciudad de Santo André, en la región metropolitana de São Paulo, que apuntó como la principal demanda de la población un buen empleo. Un presupuesto de aproximadamente $\mathrm{R} \$ 400$ millones e inversiones municipales en sectores estratégicos, como educación y salud, elevaron la clasificación del municipio, junto al Índice Paulista de Responsabilidad Social (Seade, 2004) de Municipio "Económicamente Dinámico y de Bajo Desarrollo Social" a "Municipio Polo". Entonces, ¿qué sería un buen empleo para una ciudad que ya tiene las mejores tasas de empleo y renta del país?

La segmentación socioocupacional y el Criterio Brasil muestran que la propia división socioeconómica en un determinado territorio no debe ser tomada como un dato neutro y sí como una construcción conceptual y metodológica -como objeto de investigación.

\section{La ilusión de la realidad extrema}

Con las tecnologías avanzadas de observación y representación espacial y con actualizaciones de datos en tiempo real, existe la ilusión de que la precisión absoluta está próxima, que ya no existirán impedimentos de generalizaciones espaciales (como divisiones geoadministrativas) y temporales (con proyecciones es- 
tadísticas en los intervalos de las investigaciones de campo). Una ilusión peligrosa.

La figura II, de la NASA, que muestra el mundo iluminado en agosto del 2002, es ampliamente conocida. Esta imagen es de un realismo impresionante: se observan todos los contornos de los continentes sin divisiones político-administrativas, y se concentra sólo en la iluminación nocturna del mundo. Ese realismo extremo es en verdad una pura representación, manipulada en todos los detalles. Ese mundo no existe.

Primero porque contiene todos los puntos de un geoide en un único plano. Para que vayamos al fondo de la cuestión, esa planificación de la Tierra tiene como base la Proyección de Mercator, uno de los posibles modelos de representación planimétrica del planeta, donde están incluidas las decisiones metodológicas e ideológicas (Duarte, 2002; Randles, 1994).

Además, el hecho de que sea de noche en todos los puntos del planeta al mismo tiempo -lo que, además de las implicaciones termodinámicas inherentes- hiere el principio de la rotación de la Tierra. Finalmente, también con implicaciones atmosféricas serias, la ausencia completa de nebulosidad. Esa imagen es ficción, -como otras imágenes que usamos como instrumento de investigación.

Como en otros casos de construcción de representaciones de una realidad, ella permite importantes inferencias: relacionar la densidad poblacional, la tasa de urbanización y la riqueza de regiones con mayor concentración de iluminación nocturna. Pero es simplemente una representación. Así como en la figura III, donde vemos la relación directa entre el consumo de Coca-Cola por habitante como un indicador de riqueza de las naciones.

Complementan el mapa las gráficas con la cantidad de gaseosa consumida por persona (véase figura IV) y la relación entre el consumo de Coca-Cola por habitante con el PIB per cápita de los países (véase figura v), también tomado como indicador de riqueza.

Ese cruce de datos, principalmente con la intención expresa en los gráficos y en el mapa (de que hay una relación directa entre la riqueza de las naciones y el consumo de Coca-Cola), genera inferencias asombrosas. Por ejemplo, cuando vemos que las islas de Saint Maarteen, Islas Vírgenes y Aruba tienen un altísimo consumo de gaseosa. Si la relación fuese de hecho de riqueza per cápita con el consumo per cápita de Coca-Cola, la conclusión es que las poblaciones ricas y saciadas de gaseosa, 


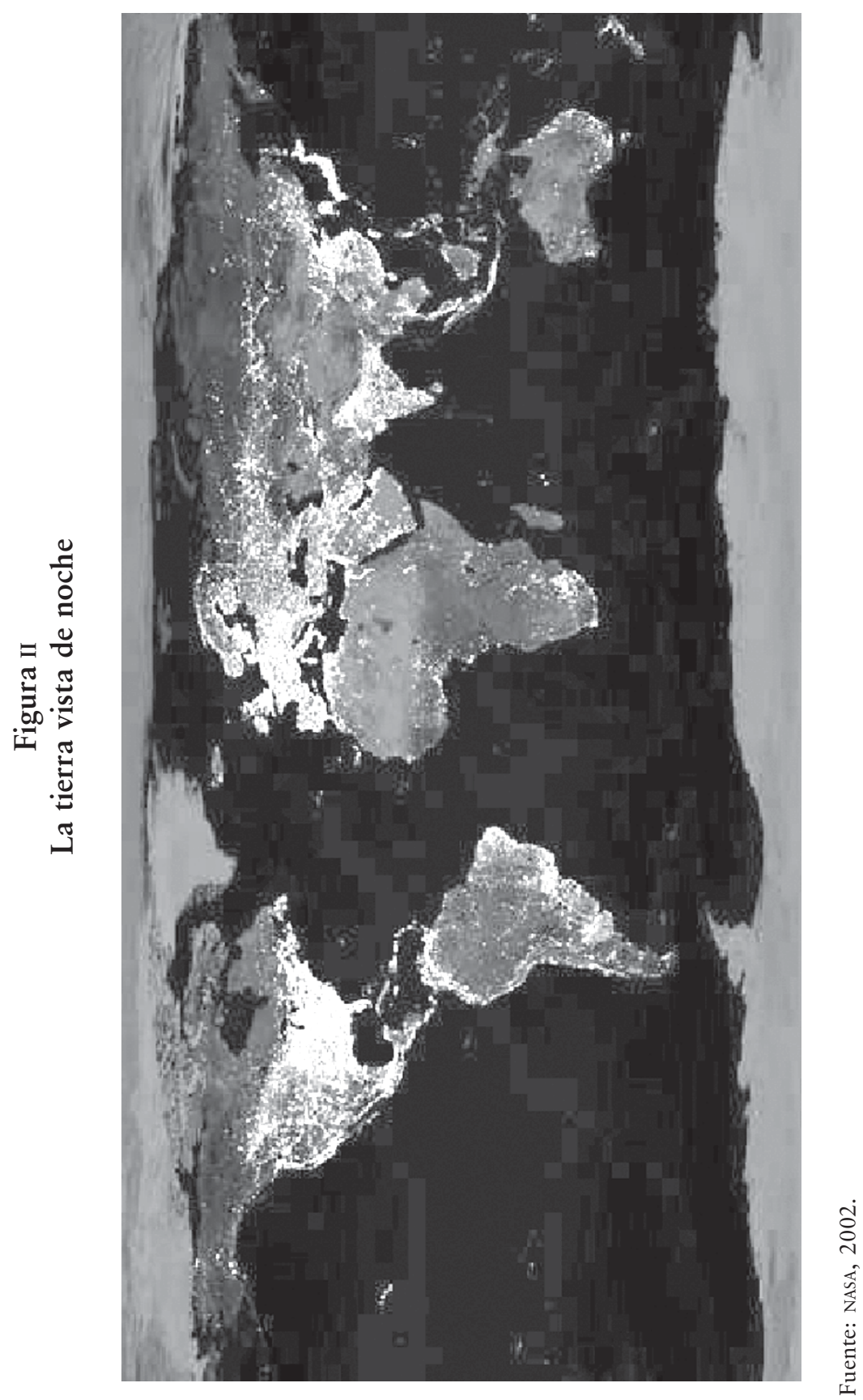




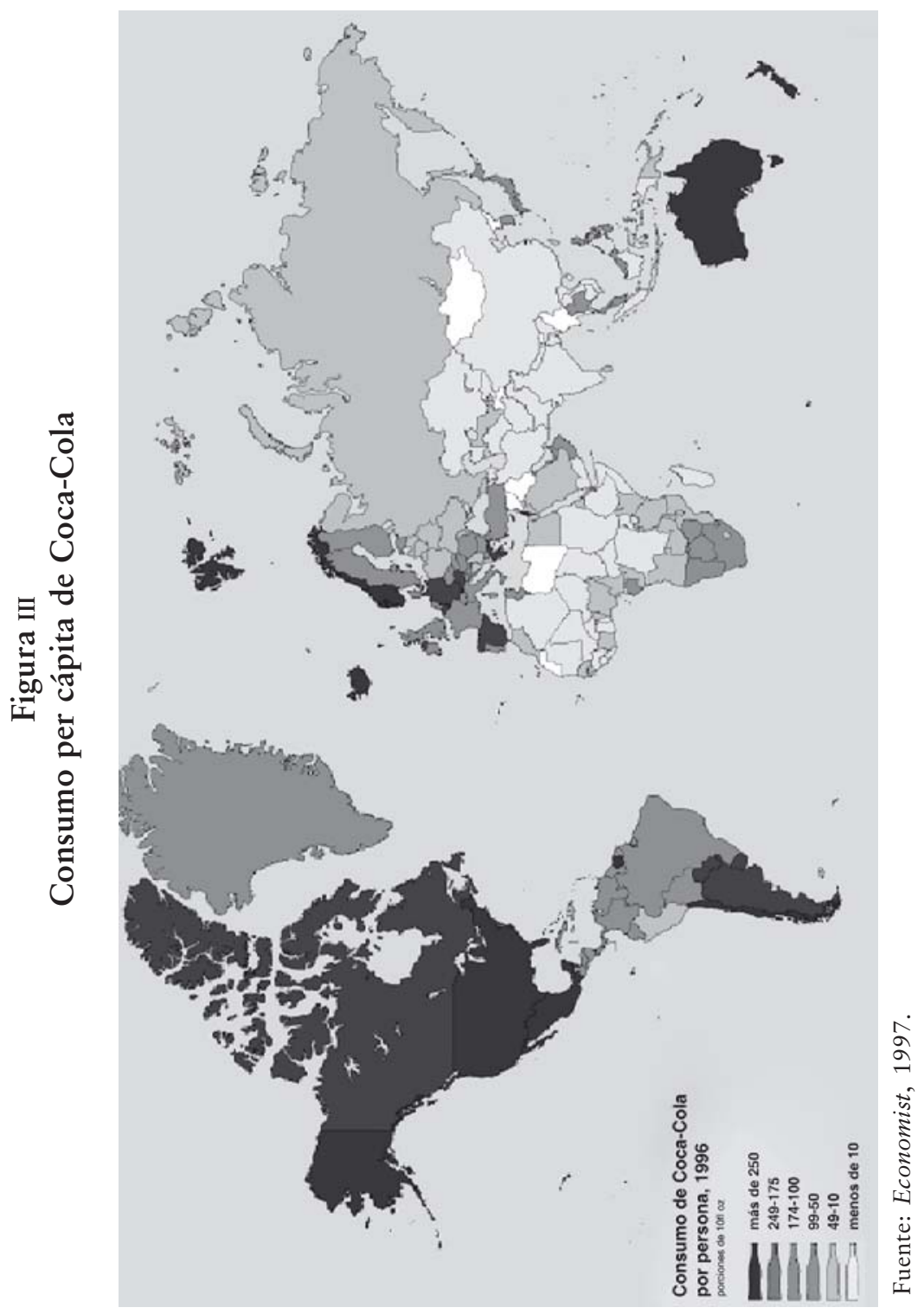



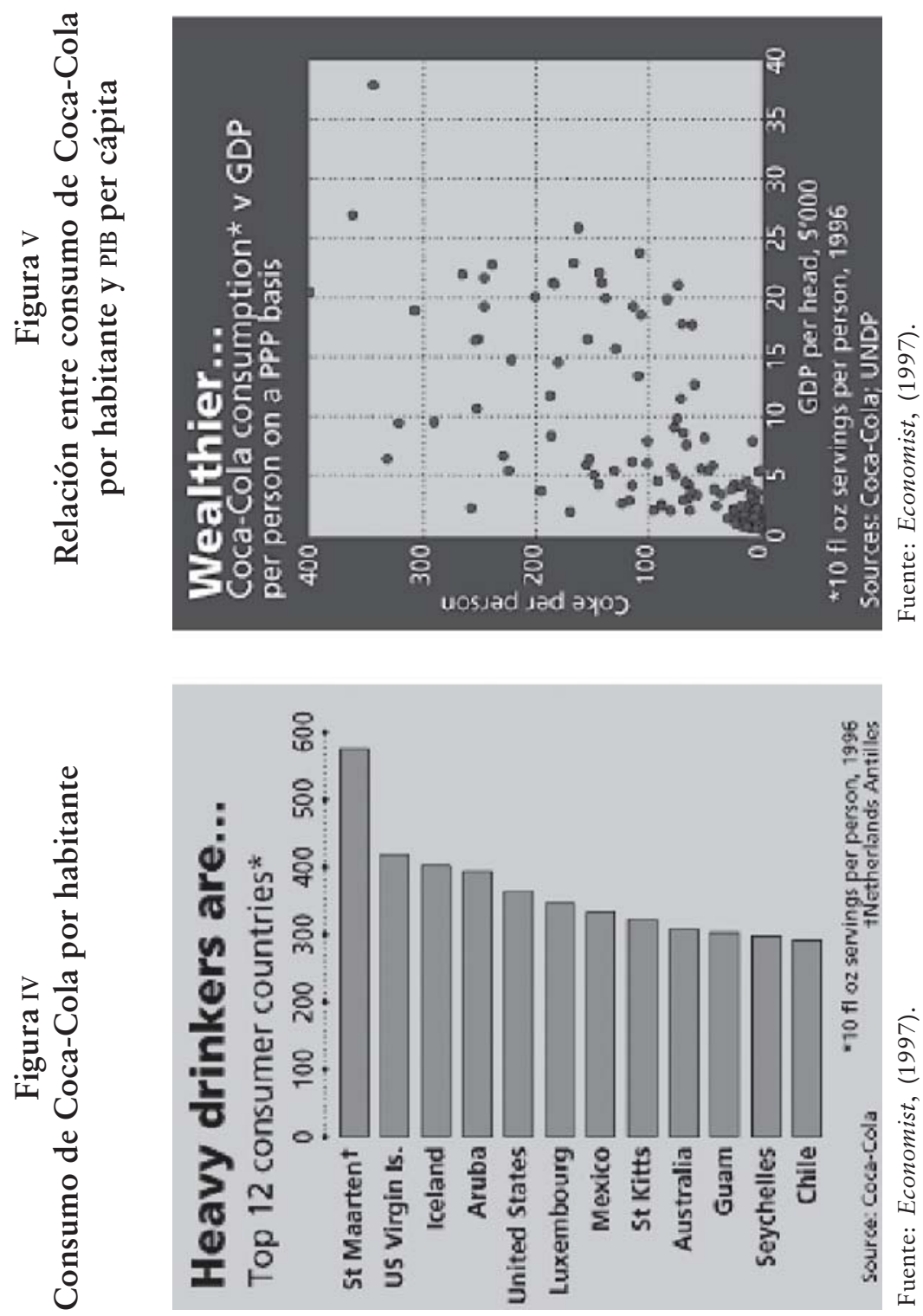
viven en paraísos tropicales. Éste no es el caso. Las tres islas tienen un flujo considerable de turistas, mucho más grande que la población residente -en Saint Maarteen, por ejemplo, hay 475 mil turistas por año para una población de 32 mil personas (UNWTO, 2005)-, y el turismo es responsable de gran parte del PIB; y en Aruba, en 78\% (wTTC, 2006). Cuando la cantidad de gaseosa consumida por esos turistas se divide entre la población residente, llegamos a esos altos valores de consumo per cápita, lo que colocaría la isla Saint Maarteen entre los países con la población más rica del mundo.

Claro que esas inferencias son engañosas, pues provienen de una construcción de la representación de la realidad. Coca-Cola sabe eso. Lo que nos interesa como investigadores es justamente tener conciencia de que la foto de la NASA también es una construcción, una abstracción de la realidad.

\section{Tasa geométrica de crecimiento... de municipios}

Para la investigación regional, siempre existe una adopción o construcción de unidades geográficas para recopilar, agregar y analizar datos. Debe haber un equilibrio entre la precisión y los detalles necesarios de los datos, conservando la posibilidad de comparaciones entre otras unidades o la misma, a lo largo del tiempo.

En Brasil, las unidades geoadministrativas menores son los municipios. La variación en sus dimensiones (Altamira, con $159,696 \mathrm{~km}^{2}$ y 77 mil habitantes, y São Pedro, en el estado de São Paulo, con $618 \mathrm{~km}^{2}$ y 32 mil habitantes) causa algunas dificultades para las comparaciones intermunicipales; pero son variaciones de dimensiones que ocurren en otros países y que con ciertas reservas, ya no causan problemas.

De hecho, las dificultades comienzan cuando en tres bases del propio IBGE (www.ibge.org.br) la información sobre el número de municipios brasileños varía entre 5,508 y 5,560: en el Sistema IBGE de Recuperación Automática (SIDRA) dependiendo del área de análisis, a 5,507 en el portal Ciudades@ (www.ibge.gov.br/ cidadesat).

Pero esta variación tiene una explicación que, lejos de resolver el problema, lo intensifica. En el cuadro 1 se presenta el número de municipios por región de Brasil entre 1970 y 2000.

El crecimiento es tanto que podemos calcular, por decenio, el porcentaje de nuevos municipios creados por región, como se muestra en el cuadro 2. 


\section{Cuadro 1}

Número de municipios por región entre 1970 y 2000

\begin{tabular}{lrrrrr}
\hline Regiones & 1970 & 1980 & 1991 & 1996 & 2000 \\
\hline Brasil & 3952 & 3954 & 4491 & 5507 & 5561 \\
Norte & 143 & 153 & 298 & 449 & 449 \\
Nordeste & 1376 & 1375 & 1.509 & 1.787 & 1.792 \\
Sudeste & 1410 & 1410 & 1.432 & 1.666 & 1.668 \\
Sur & 717 & 719 & 873 & 1.159 & 1.189 \\
Centro-Oeste & 306 & 317 & 379 & 446 & 463 \\
\hline
\end{tabular}

Fuente: IBGE (1970-2000).

\section{Cuadro 2}

Porcentaje de crecimiento en el número de municipios por región

\begin{tabular}{lcc}
\hline Regiones & 1980 a 1990 & 1991 a 2000 \\
\hline Brasil & $13 \%$ & $24 \%$ \\
Norte & $95 \%$ & $51 \%$ \\
Nordeste & $10 \%$ & $19 \%$ \\
Sudeste & $2 \%$ & $16 \%$ \\
Sur & $21 \%$ & $36 \%$ \\
Centro-Oeste & $20 \%$ & $22 \%$ \\
\hline
\end{tabular}

Fuente: IBGE (1980, 1991 y 2000).

O aún más, el número de municipios creados en Brasil por año, haciendo de este país probablemente el único donde se puede calcular una tasa anual de crecimiento de unidades municipales.

Sabemos que la creación de tantos municipios tiene explicaciones de orden político. Sin embargo, la cuestión en este artículo es resaltar la dificultad de realizar investigaciones histórico-regionales con comparaciones de datos, debido a la gran diversidad de unidades existentes entre uno y otro periodos de la investigación. También corremos peligro si, incautos, realizamos comparaciones, por ejemplo, sobre un simple dato (neutro, como fue expuesto arriba) como el número de habitantes de un municipio de un año a otro sin considerar que un municipio analizado en el primer periodo ya no es el mismo en sus dimensiones y límites en el periodo posterior. Sin esa consideración, el análisis puede ser, al menos, incorrecto, pero, más grave aún, tendencioso. Si fueran casos aislados, los arreglos se podrían hacer en el momento de la investiga- 
ción; pero cuando una región tiene un aumento de 95\% en el número de municipios en un decenio, seguido por un aumento de $51 \%$, esas correcciones son prácticamente imposibles.

\section{Consideraciones finales}

En este ensayo buscamos analizar una importante suposición sobre las investigaciones urbanas y regionales que trabajan con datos secundarios, involucrando aspectos geográficos, sociales, económicos, etcétera: la suposición de que la investigación urbana se realiza fundamentalmente sobre una realidad abstracta. Esto es un facto conocido por los investigadores. Nuestra intención ha sido demostrar que una investigación empieza con procesos de abstracciones y reducciones que el estudioso debe hacer para transformar el contacto con la realidad en material manipulable. Ese proceso de abstracción y reducción forma las representaciones de la realidad, materia prima de importantes fases de la investigación científica.

Hemos expuesto que aunque en apariencia los datos son muy próximos a la realidad, son construcciones de representación bastante elaboradas pero, finalmente, representaciones.

Por último, la atención se podría dirigir a la importancia de que los propios procesos de construcción de esas realidades abstractas sean explorados por los investigadores, ya que tales procesos revelan presuposiciones epistemológicas, ideológicas y de lenguaje que alteran definitivamente el análisis de la situación investigada. El profundo conocimiento de la realidad pasa, necesariamente, por el conocimiento de la construcción de sus representaciones.

\section{Bibliografía}

ABEP (Asociación Brasileña de Empresas de Investigación) (2003), Critério de classificação econômica Brasil, ABEP, São Paulo, disponible en <http://www.abep.org.br>.

Borges, Jorge Luis (1960), “Del rigor de la ciencia”, en El Hacedor, Emecé, Buenos Aires.

Calvino, Italo (1972), Las ciudades invisibles, Minotauro, Buenos Aires. 
Duarte-de Araújo-Silva, Fabio (2002), Crise das matrizes espaciais, Perspectiva-Fapesp, São Paulo.

Ferrara d'Alessio, Lucrécia (2003), Design em espaços, Rosari, São Paulo.

IBGE (Instituto Brasileño de Geografía y Estadística) (1970), Censo Demográfico, IBGE, Brasilia.

IBGE (Instituto Brasileño de Geografía y Estadística) (1980), Censo Demográfico, IBGE, Brasilia.

IBGE (Instituto Brasileño de Geografía y Estadística) (1991), Censo Demográfico, IBGE, Brasilia.

IBGE (Instituto Brasileño de Geografía y Estadística) (2000), Censo Demográfico, IBGE, Brasilia.

IBGE (Instituto Brasileño de Geografía y Estadística) (2002), Pesquisa Nacional por Amostra Domiciliar, IBGE, Brasilia.

IBGE (Instituto Brasileño de Geografía y Estadística) (2003), Economia Informal Urbana, IBGE, Brasilia, documento html en: <http://www.ibge.gov.br/home/estatistica/economia/ ecinf/2003/default.shtm $>$.

IBGE (Instituto Brasileño de Geografía y Estadística) (2005), Pesquisa Mensal de Emprego - nova metodología, IBGE, documento html en: <http://www.ibge.gov.br/brasil_em_sintese/ default.htm $>$.

Jannuzzi, Paulo de Martino (2003), "Estratificação socioocupacional para estudos de mercado e pesquisa social no Brasil”, São Paulo em Perspectiva, 17 (3-4): 247-254 (juliodiciembre).

NOP (Nucleo de Opinião Pública) (2003), Discriminação racial e preconceito de cor no Brasil, Fundação Perseu Abramo e Rosa Luxemburg-Stufting, documento html en: <http:// www.fpabramo.org.br/nop/racismo/index.htm $>$.

Peirce, Charles Sanders (1977), Semiótica, Perspectiva, São Paulo. 
Randles, W. G. L. (1994), Da terra plana ao globo terrestre, Papirus, Campinas.

Santos, M., y M. L. Silveira (2003), O Brasil: território e sociedade no início do século XXI, Record, Río de Janeiro.

SEADE (Sistema Estatal de Análisis de Datos) (2004), Índice Paulista de Responsabilidade Social, SEAdE, São Paulo, documento en: <http:/www.al.sp.gov.br/web/forum/iprs03/ index_iprs.htm $>$.

UNDP (2005), Human Development Reports 14 - Economic Performance, UNDP, United Nations Development Programme.

UNwTo (United Nations World Tourism Organization) (2005), Tourism Market Trends, UNWTO.

wTTC (World Travel and Tourism Council) (2006), Tourism Satellite Accounting Highlights, wTTC. (www.wttc.org/ framesetsitemap.htm).

Recibido: 23 de junio de 2006. Reenviado: 2 de octubre de 2006. Aprobado: 16 de noviembre de 2006.

Fábio Duarte-de Araújo-Silva, es urbanista y doctor en comunicaciones por la Universidad de São Paulo. Actualmente es profesor investigador en la maestría en gestión urbana en la Pontificia Universidad Católica de Paraná, en Curitiba (PUCPR). Ha sido investigador en el Centre de Recherches en Aménagement et Développement de la Université Laval, Canadá, 1998-1999, y en el Departamento de Geografía de la Universidad París I - Sorbonne, Francia, 1999-2000. Su línea de investigación se centra en Redes sociotécnicas urbanas y socioeconomía urbana en la PUCPR. Entre sus publicaciones destacan: "Crise das matrizes espaciais. São Paulo, Perspectiva, 2002; "Pensar la ciudad en red", Urbano, 9, Chile (2006); "Démocratie participative et gouvernance interactive au Brésil: Santos, Porto Alegre et Curitiba" (en coautoría con K. Frey), Espaces \& Sociétés, 123 (4): 99-112 (2005). 